\title{
Controle sanitário de agrotóxicos no Brasil: o caso do Metamidofós
}

\author{
Sanitary pesticides control in Brazil: the case of methamidophos \\ Control Sanitario de los pesticidas en Brasil: el caso de Metamidofos
}

Katiuscia Moreira de Oliveira ${ }^{1}$

\begin{abstract}
RESUMO: Neste trabalho foram analisados os riscos à saúde relacionados ao uso do agrotóxico Metamidofós no Brasil e as principais dificuldades que a autoridade sanitária enfrenta na realização da avaliação destes riscos e de seu gerenciamento. A partir dos dados sobre o cancelamento do registro do Metamidofós procedeu-se uma busca sobre todo o processo da sua reavaliação toxicológica. Os fatos relacionados à reavaliação e cancelamento do Metamidofós mostraram a importância da existência do controle sanitário, bem como a necessidade de constantes reavaliações das tecnologias empregadas na produção agrícola brasileira. Os agricultores se acostumaram ao uso do Metamidofós e a sua reavaliação ameaçou interesses econômicos. Porém a legislação específica dá aos poderes públicos competências para realizarem seu controle sanitário e a reavaliação sistemática de seu uso. O controle sanitário identifica distorções e os conhecimentos trazem informações e evidências sobre os riscos para a saúde e ambiente.
\end{abstract}

Palavras-chave: Organofosforado. Reavaliação Toxicológica. Risco. Saúde Humana.

ABSTRACT The objective this work was gather and analyze information about the health risks related to use of the Methamidophos pesticide in Brazil and the main difficulties facing the health authority in performing the assessment and control these risks. From the data on the registration cancellation of Methamidophos was carried out a search on the whole process of its toxicological revaluation. The facts related to revaluation and cancellation of Methamidophos showed the importance of sanitary control and the need for constant review of the technologies employed in Brazilian agricultural production. Farmers accustomed to using Methamidophos, saw in the revaluation, a threat to of them economic interests. However, the specific legislation gives government powers to carry out sanitary control and systematic revaluation of pesticide use. The sanitary control identifies distortions and the knowledge provides information and evidence about the risks to health and environment.

Keywords: Organophosphate. Toxicological Revaluation. Risk. Human Health.

RESUMEN: El objetivo de este trabajo fue recopilar y analizar información sobre los riesgos para la salud con el uso del plaguicida metamidofos en Brasil y las principales dificultades de la autoridad sanitaria en la realización de la evaluación y el control de estos riesgos. Desde los datos de la cancelación de la inscripción de metamidofos se llevó una búsqueda en todo el proceso de su revalorización toxicológica. Los hechos relacionados con la revalorización y la cancelación de metamidofos mostraron la

\footnotetext{
${ }^{1}$ Fonoaudióloga. Email: katiuchiafono@gmail.com.
} 
importancia del control sanitario y la necesidad de una revisión constante de las tecnologías empleadas en la producción agrícola brasileña. Los agricultores acostumbrados a utilizar metamidofos, han visto en la revalorización, una amenaza de los intereses económicos para ellos. Sin embargo, la legislación de los poderes públicos para el control sanitario y la revaluación sistemática del uso de plaguicidas. El control sanitario identifica las distorsiones y el conocimiento proporciona información y pruebas sobre los riesgos para la salud y el medio ambiente.

Palabras-llave: Organofosforados. Revalorización toxicológica. Riesgo. Salud Humana.

\section{Introdução}

O uso abusivo de agrotóxicos vem causando preocupação em todo o mundo devido aos efeitos adversos que pode causar a saúde humana e ao meio ambiente. Esses efeitos são, na maioria das vezes, condicionados por fatores como alta toxicidade dos produtos, uso inadequado e falta de utilização de equipamentos de proteção coletiva e individual. Esta situação é agravada pelas precárias condições socioeconômicas e culturais da grande maioria dos trabalhadores rurais, o que amplia sua vulnerabilidade frente à toxicidade dos agrotóxicos (1), (2).

No Brasil o termo "agrotóxico" é usado para denominar as substâncias tóxicas utilizadas para matar, controlar ou afastar organismos indesejados da lavoura e, ou, da área urbana, tais como: fungicidas, herbicidas, inseticidas, acaricidas, bactericidas, entre outros (3). É comum a defesa do termo "defensivo agrícola" em vários segmentos acadêmicos e empresariais. O termo "agrotóxico" ao invés de "defensivo agrícola" passou a ser utilizado, no Brasil, para denominar os venenos agrícolas, após grande mobilização da sociedade civil organizada. Mais do que uma simples mudança da terminologia, esse termo coloca em evidência a toxicidade desses produtos para o meio ambiente e a saúde humana. São ainda genericamente denominados praguicidas ou pesticidas (4)

Apenas entre 2000 e 2010 o uso de agrotóxicos cresceu 93\% em todo o mundo. No Brasil esse percentual foi muito superior, chegando a 190\%. São cerca de 130 empresas produtoras instaladas fabricando aproximadamente 2.400 produtos diferentes (5). O Brasil é, na atualidade, o maior consumidor de agrotóxicos, sendo responsável por $1 / 5$ do consumo mundial (6). Isto significa dizer que $19 \%$ de todos os defensivos agrícolas produzidos no mundo são utilizados no Brasil. Em 2010, foram vendidas 936 mil toneladas de agrotóxicos, o que movimentou 7,3 bilhões de dólares (7) 
Os agravos causados pelos agrotóxicos determinam um problema muito sério de saúde pública, principalmente no que diz respeito à saúde dos agricultores e, é claro, a saúde dos consumidores. Por isso, no Brasil, o registro de um agrotóxico necessita de análise e concordância de três órgãos: o Ministério da Agricultura, Pecuária e Abastecimento (MAPA), a Agência Nacional de Vigilância Sanitária (ANVISA) e o Instituto Brasileiro de Meio Ambiente (IBAMA) (8)

A ANVISA é o órgão responsável no âmbito do Ministério da Saúde pela avaliação da toxicidade dos agrotóxicos e seus impactos à saúde humana, emitindo um parecer toxicológico favorável ou desfavorável à concessão do registro pelo Ministério da Agricultura. A partir do ano de 2000 a ANVISA deu início aos processos de reavaliações toxicológicas de alguns agrotóxicos que já estavam registrados para comercialização no Brasil por apresentarem alterações de risco à saúde humana (9)

A avaliação do risco é um processo que envolve equipe multidisciplinar visando organização e análise de informações cientificas disponíveis relacionadas aos efeitos adversos de uma substancia química, com a finalidade de estabelecer suas probabilidades e magnitude e permitir ao gestor, principalmente, promover a redução da frequência dos eventos adversos identificados (10).

No ano de 2001 a ANVISA instituiu o Programa de Análise de Resíduos de Agrotóxicos em Alimentos (PARA). O principal objetivo deste programa é avaliar os níveis de resíduos de agrotóxicos nos alimentos in natura que chegam aos consumidores (7).

Entre os diversos resultados do PARA, evidenciou-se a utilização do Metamidofós² em culturas para as quais o seu uso não estava autorizado, tais como alface, arroz, cenoura, mamão, morango, pimentão, repolho e uva. Resíduos deste agrotóxico foram detectados também em tomate de mesa, cultura para a qual o seu uso estava restringido pela ANVISA, o que por si só demonstrava o agravo da situação (7). Os resultados alcançados com o PARA confirmam que o uso de agrotóxicos não autorizados, como o Metamidofós, e a presença de resíduos acima do limite máximo permitido continuam frequentes. Isso fez surgir a necessidade de adoção de medidas mais eficientes de controle e fiscalização, o que levou a decisão da ANVISA de

\footnotetext{
2 Agrotóxico organofosforado que age em insetos e mamíferos diminuindo a atividade da enzima acetilcolinesterase, essencial na transmissão normal de impulsos nervosos.
} 
implementar a reavaliação de uma série de agrotóxicos, proposta da RDC ํo 10 de 22/02/2008 (11). Esta decisão teve amparo legal na Lei 7.802/1989 e no Decreto 4.074/2002. Esta medida tem feito com que os representantes de empresas fabricantes de agrotóxicos movam ações judiciais no sentido de impedir que tal reavaliação aconteça (9).

Pesquisas nacionais e internacionais, bem como condenações judiciais das empresas fabricantes de agrotóxicos por agravos a saúde das pessoas, no exterior, influenciaram a ANVISA a tomar esta decisão, visando à prevenção de riscos à vida e a saúde da população brasileira consumidora dos hortifrutigranjeiros tratados com estes produtos, bem como trabalhadores rurais que os manejam (9)

Dentre os grupos de agrotóxicos mais combatidos, merecem destaque os organoclorados, hoje proibidos em todo o mundo, os carbamatos e mais recentemente, os organofosforados. O Metamidofós é um desses organofosforados que tem causado muitos problemas à saúde pública no Brasil, estando envolvido em diversas ações judiciais. A interferência do poder econômico de empresas que fabricam, transportam e comercializam este agrotóxico no Brasil fez com que as mesmas entrassem com demandas judiciais contra a agência regulatória visando impedir o cancelamento de seu registro. A reavaliação e cancelamento do Metamidofós é um exemplo, um caso emblemático dos problemas que os agrotóxicos podem causar a saúde humana e as dificuldades de realização do seu controle sanitário.

Sendo assim, neste trabalho objetivou-se analisar os riscos à saúde relacionados ao uso do agrotóxico Metamidofós no Brasil e demonstrar as dificuldades de realizar o seu controle sanitário.

Neste sentido, o questionamento principal que orientou este estudo foi: quais são os principais riscos à saúde decorrentes do uso do agrotóxico Metamidofós e quais as principais dificuldades que a autoridade sanitária enfrenta na realização da avaliação destes riscos e de seu gerenciamento. Em outras palavras, quais as principais dificuldades que a ANVISA encontra para fazer o controle sanitário deste agrotóxico e assim realizar sua missão de proteção à saúde da população brasileira. 


\section{Metodologia}

Tratou-se de um estudo descritivo-exploratória de caso, de abordagem qualitativa, baseada em articulação metodológica que inclui a revisão sistemática da literatura de referência, com a organização de informações sobre o agrotóxico Metamidofós, a análise da legislação correlata a este agrotóxico e aspectos do processo de sua reavaliação.

As informações sobre o Metamidofós foram organizadas: a) sua classe química; b) toxicidade à saúde humana; c) potencial de ação em exposições agudas e crônicas; d) potencial de interferência com os compartimentos ambientais e a biota; e) comparação com o controle e a autorização de seu uso na agricultura.

As principais fontes literárias sobre o agrotóxico foram os portais da ANVISA, do MAPA, da Fundação Oswaldo Cruz (Fiocruz), do Tribunal Regional Federal (TRF) $1^{\underline{a}}$ região, além de pesquisa ampla na internet, envolvendo os descritores: agrotóxicos, organofosforado, Metamidofós, reavaliação e jurisprudência.

A análise da legislação pertinente compreendeu as seguintes etapas: a) identificação das leis, decretos e portarias que tratam sobre a utilização de agrotóxico no país, no âmbito federal e b) apreciação analítica da legislação, incluindo a identificação dos conceitos de agrotóxicos quando descritos em texto. Com base nas fontes consultadas, foi selecionada a bibliografia sobre agrotóxicos e depois mais especificamente sobre o agrotóxico Metamidofós.

A partir dos dados sobre o cancelamento do registro do Metamidofós, obtidos no portal da ANVISA, procedeu-se uma busca sobre todo o processo da sua reavaliação, incluindo 0 acesso ao mandado de segurança no portal do TRF $1^{\circ}$ região que tinha 0 propósito de impedir a reavaliação e cancelamento do registro do agrotóxico.

Por meio da análise dos documentos e informações acessadas foram selecionados os aspectos principais que contribuíram para a realização dos objetivos deste estudo. A redação final foi feita cruzando estas informações, inclusive a legislação sobre o assunto e as análises que elas permitiram.

Entendeu-se que estudos desse tipo contribuem para o desenvolvimento da consciência sanitária da população, desde as dificuldades que a autoridade sanitária enfrenta para realizar o controle tais como o acesso à informação cientifica de 
qualidade, enfrentamento dos interesses econômicos dentre outros fatores, até o papel do judiciário, que por influência de uma série de fatores econômicos, sociais e ambientais que permeiam este tema, encontra-se envolvido em um dilema entre a liberdade de ação dos agentes econômicos, garantida na Constituição Federal (artigo 170) e a proteção da saúde coletiva.

\section{Resultados}

\section{O agrotóxico Metamidofós}

Os agrotóxicos são classificados, controlados e legislados de maneira bastante distinta, dependendo de seu uso primário (combate a pragas em animais ou em vegetais). Conforme visto, no Brasil, a Lei 7.802/1989 regula o uso de agrotóxicos para o combate a pragas em alimentos, pastagens e vegetação natural, e prevê que esses produtos, para terem seu uso autorizado em nosso país, devem passar por avaliação de um Comitê Interministerial envolvendo: a) o Ministério da Agricultura, Pecuária e Abastecimento, que avalia a eficiência agronômica dos produtos; b) O Ministério do Meio Ambiente, que avalia o potencial tóxico desses agentes para o ambiente e a biota; e, c) o Ministério da Saúde, que avalia a toxicidade desses produtos à saúde humana (12).

A reavaliação do agrotóxico no Brasil é coordenada pela ANVISA e enfrenta muitas pressões econômicas que tentam impedir o andamento do processo. Somam-se a isto as pressões políticas e as divergências no governo. Por isso o processo de reavaliação no Brasil é considerado lento e, muitas vezes, envolve etapas de judicialização (13) A reavaliação de produtos técnicos e formulados à base do ingrediente ativo Metamidofós sustenta-se na RDC n 10, de 22 de fevereiro de 2008, que estabelece sua reavaliação toxicológica.

Os resultados das avaliações em 2008 revelaram o uso não autorizado de Metamidofós em culturas de alface, arroz, batata, feijão, laranja, mamão, morango, pimentão, repolho, tomate e uva. Trata-se de grande problema de saúde pública, pois esses alimentos são geralmente consumidos in natura e fazem parte dos hábitos alimentares da população brasileira (11). 
O manuseio e aplicação do Metamidofós expõem trabalhadores ao risco de morte na atividade agrícola. As intoxicações e óbitos estão relacionados às características de toxicidade desse princípio ativo. Além disto, diversas questões de ordem social (baixa escolaridade, baixa renda) e biológica (idade e gênero) são fatores que aumentam a vulnerabilidade e a gravidade das intoxicações por esse organofosforado (1); (2)

A ANVISA, devido a suspeita de danos à saúde, diante de alertas ou suspeitas de efeitos adversos que se configuram dentre os proibitivos de registro, publicou a reavaliação do Metamidofós, que possui vários efeitos adversos para a saúde humana, além de ser extremamente tóxico (Classe I) (11). De acordo com a Lei 7.802/89 um agrotóxico se enquadra nas proibições de registro quando há ausência de métodos para desativação do produto, na ausência de antídoto ou tratamento eficaz, quando provoca distúrbios hormonais ou danos ao aparelho reprodutor e, quando são teratogênicos, carcinogênicos ou mutagênicos. Além disso, também quando se apresenta mais perigoso para o homem do que em animais (12).

O Metamidofós é um agrotóxico organofosforado que age em insetos e mamíferos diminuindo a atividade da enzima acetilcolinesterase, essencial na transmissão normal de impulsos nervosos (13). Seu efeito nocivo é prolongado, pois apresenta efeito residual de 10 a 12 dias.

Seu uso na agricultura brasileira foi crescente na década de 90 , sendo que foram registrados casos de uso abusivo e indiscriminado e de contaminação em culturas de hortaliças (14); (15). Além de ser altamente tóxico aos mamíferos, aves e insetos, o Metamidofós produz desgaste dos equipamentos de proteção individual (EPI), como respiradores, óculos de proteção para químicos, luvas de borracha e roupas protetoras impermeáveis (16)

No campo da saúde, o efeito nocivo do Metamidofós tem sido observado no fígado, baço, rins, órgãos genitais e pulmões. Para os efeitos subagudos ou subcrônicos observou-se alteração do peso absoluto dos órgãos dos animais testados. A desregulação endócrina causada pelo Metamidofós é um efeito adverso muito preocupante do ponto de vista da saúde pública e ambiental, pois pode desencadear efeitos seriamente debilitantes e até a morte. Por possuírem o potencial de interferir com a reprodução, já que os eixos de regulação hormonal estão integrados, os 
desreguladores endócrinos podem alterar, entre outros, o número de indivíduos de uma determinada população. Esses efeitos podem repercutir nos ecossistemas e, por conseguinte, nas populações humanas. A intoxicação aguda por Metamidofós induz uma série de efeitos deletérios sobre a saúde de humanos e animais).

Podem ocorrer manifestações menos graves como vômito, diarréia, sudorese excessiva, salivação, lacrimejamento, miose, broncoconstrição, cólicas abdominais, bradicardia, taquicardia, dor de cabeça, tontura, cansaço, ansiedade, confusão mental e visão turva. Entretanto, em casos mais graves pode ocorrer convulsão, depressão do centro respiratório, fasciculação dos músculos respiratórios com paralisia muscular, parada respiratória, coma e morte (7)

A contaminação do meio ambiente pode ocorrer de diversas formas: poluindo o ar, através de pulverizações, o solo, quando produtos são usados diretamente e de forma incorreta nas lavouras, e a água, quando em períodos de chuvas esses compostos químicos penetram o solo e alcançam lençóis freáticos e leitos de rios. Ainda considerase que mesmo de forma indireta, agrotóxicos afetam também a vida animal (17).

Pelo conjunto de efeitos nocivos do Metamidofós à saúde humana, especialmente, relacionado à neurotoxicidade, imunotoxicidade e sobre o sistema endócrino, reprodutor e desenvolvimento embriofetal, foi recomendado à proibição do Metamidofós na atividade agrícola e em outras que possibilite a exposição humana (7).

\section{Fundamentos de reavaliação toxicológica}

O controle da produção, da comercialização e do emprego de técnicas, métodos e substâncias que comportem risco para a vida, para a qualidade de vida e para meio ambiente, são incumbências do Poder Público, atribuídas pelo artigo 225 da Constituição Federal, e regulamentado no caso específico dos agrotóxicos, pela Lei 7.802, de 11 de julho de 1989.

Segundo a Lei 7.802/89 são considerados agrotóxicos e afins todos os produtos e agentes de processos físicos, químicos ou biológicos usados na área agrícola, na proteção florestal, em outros ecossistemas e em áreas urbanas, com o objetivo de combater pragas ou doenças causadas pela ação danosa de seres vivos considerados nocivos (18) 
O agrotóxico é tido como uma categoria estabelecida em lei, resultando em uma terminologia jurídica, com implicações próprias e que convive com toda a diversidade terminológica acerca dos produtos incluídos na delimitação legal, não se referindo apenas a substâncias, mas de forma mais abrangente também a produtos e agentes físicos, químicos ou biológicos (19). Essa diversidade terminológica pode gerar diferentes compreensões.

O Poder Legislativo reconhecendo os efeitos danosos dos agrotóxicos estabeleceu, no artigo $3^{\circ}$ da Lei 7.802/89, as proibições de registro. Dessa forma os agrotóxicos, para a obtenção do registro, são avaliados e reavaliados quanto aos impactos à saúde humana, ao meio ambiente e de eficácia agronômica.

A reavaliação de registro se dá para produtos que já se encontram registrados no Brasil. A partir desta entrada, os mecanismos de reavaliações do registro dependem exclusivamente dos órgãos federais: Ministérios Agricultura, Saúde e Ambiente no âmbito de suas respectivas áreas de competência, terem a capacidade para identificar a necessidade e promover a reavaliação do registro, ou seja, do retorno à etapa inicial do processo. É o que dispõe o Decreto 4.074 de 2002:

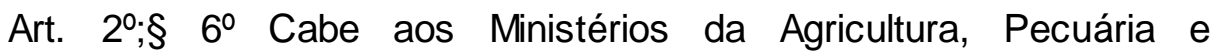 Abastecimento, Saúde e do Meio Ambiente, no âmbito de suas respectivas áreas de competências: promover a reavaliação de registro de agrotóxicos seus componentes e afins quando surgirem indícios da ocorrência de riscos que desaconselhem o uso de produtos registrados ou quando o País for alertado nesse sentido, por organizações internacionais responsáveis pela saúde, alimentação ou meio ambiente, das quais o Brasil seja membro integrante ou signatário de acordos (12)

O mesmo decreto, no artigo 19², parágrafo único, incisos I a VII, prevê, de acordo com os resultados das reavaliações, que se pode manter o registro sem alterações; manter o registro, mediante a necessária adequação, propor a mudança da formulação, dose ou método de aplicação; restringir a comercialização; proibir, suspender ou restringir a produção ou importação; proibir, suspender ou restringir o uso; e cancelar ou suspender o registro (12)

Foi considerando o acima exposto, bem como o banimento ou restrições de utilização de ingredientes ativos no cenário internacional, que a ANVISA, em um 
trabalho conjunto com a Fiocruz, realizou a reavaliação toxicológica do ingrediente ativo Metamidofós (RDC no 10, de 22 de fevereiro de 2008).

Vários motivos subsidiaram esta reavaliação, tais como a inclusão do metamidofós na lista PIC (Previous Informed Consent) da Convenção de Roterdã, sua elevada toxicidade aguda, neurotoxicidade, imunotoxicidade e toxicidade sobre o sistema endócrino, reprodutor e desenvolvimento embriofetal; e a proibição de seu registro e as severas restrições devido aos riscos para a saúde humana no cenário internacional. (7).

Para a decisão da ANVISA foram considerados todos os estudos apresentados na própria Agência e publicações na literatura científica, considerando também decisões em outras agências regulatórias. Foi com esse conjunto de evidências sobre os graves efeitos negativos do Metamidofós, principalmente em seres vivos, e lembrando ainda o recurso do princípio da precaução que também procede no caso, é que se recomendou a proibição deste agrotóxico no Brasil (7) ANVISA, 2012b)

O Princípio da Precaução tem relação com o estado do conhecimento sobre um produto, considerando três situações características: a) ignorância, onde nem a probabilidade de ocorrência de um evento e nem a magnitude de seus efeitos são conhecidos; b) incertezas, quando os efeitos são conhecidos, mas a frequência de um efeito adverso é incerta e c) risco, quando ambas, a magnitude dos efeitos e a frequência de ocorrência, são conhecidas (20). Ações que visam proteger a saúde das pessoas e dos ecossistemas em razão do uso de substâncias nocivas podem ser questionadas na falta de dados científicos. Mas havendo suspeitas dos malefícios, esta também é uma situação em que se deve evocar o princípio da precaução, previsto na legislação brasileira (10)

\section{Os resultados da reavaliação}

Cumpridas as etapas de reavaliação e amparada em resultados de diversos estudos em diferentes regiões e instituições a ANVISA cancelou o registro de todos os agrotóxicos formulados a partir do princípio ativo Metamidofós (7)

Na Resolução-RDC № 1 de 14 de janeiro de 2011 foi publicado o regulamento técnico para o ingrediente ativo Metamidofós em decorrência da reavaliação toxicológica. A ANVISA, considerando o disposto na Lei 7.802/1989, combinado com 
disposto no Decreto 4.074/2002, considerando que o ingrediente ativo Metamidofós apresenta características neurotóxicas, imunotóxicas e provoca toxicidade sobre o sistema endócrino, reprodutor e desenvolvimento embriofetal; e que o ingrediente ativo se enquadra dentre os agrotóxicos com características proibitivas de registro; determinou a retirada programada do ingrediente ativo Metamidofós do mercado brasileiro. As empresas só poderão produzir praguicidas com o ingrediente ativo Metamidofós com base nos históricos quantitativos de comercialização de anos anteriores de cada empresa e com base nos estoques já existentes no país de matériasprimas, produtos técnicos e formulados. A comercialização destes produtos só pôde ser feita até 31 de dezembro de 2011 e a utilização, até 30 de junho de 2012. Ficou para 31 de dezembro de 2012 o cancelamento da monografia do ingrediente ativo Metamidofós, mantida até esta data exclusivamente para fins de monitoramento dos resíduos (18)

\section{Demandas Judiciais contra a reavaliação e o cancelamento do agrotóxico Metamidofós.}

Ações judiciais foram movidas por empresas produtoras de agrotóxicos instaladas no Brasil para impedir a realização das reavaliações de agrotóxicos, que foram temporariamente suspensas por força de liminares concedidas em favor das empresas. Isto ocorreu também com relação a outros agrotóxicos (5)

Em abril de 2008, a companhia japonesa Arysta $^{3}$ conseguiu um mandado de segurança que impediu a ANVISA de alterar o registro dos agrotóxicos produzidos a partir do acefato. Em julho de 2008, o Sindag ${ }^{4}$ conseguiu, com uma liminar, interromper a reavaliação de nove princípios ativos: metamidofós, triclorfom, parationa metílica, fosmete, carbofurano, forato, endosulfam, paraquate e tiran. Em agosto do mesmo ano, a italiana Sipcam ${ }^{5}$ Isagro entrou na justiça com um pedido de anulação do processo de reavaliação da cihexatina, numa tentativa de impedir que a ANVISA publicasse as restrições a esse agrotóxico. Produtos como o acefato, carbofurano, cihexatina, forato, fosmete, endosulfam, paraquate, tiram, parationa metilica e metamidofós, têm seu uso proibido ou restrito na Europa e nos Estados Unidos (21). Após moção de apoio do 
Conselho Nacional de Saúde, amplo apoio da sociedade civil organizada e recursos por parte da Advocacia Geral da União, em novembro de 2008, a ANVISA conseguiu reverter às decisões judiciais para a reavaliação de 13 substâncias ativas. Somente a reavaliação do acefato foi declarada nula, porque a justiça entendeu que não caberia sua reavaliação naquele momento. As demais reavaliações foram retomadas. (7) ANVISA, 2012c).

A empresa Fersol, fabricante do ingrediente ativo Metamidofós, em fevereiro de 2010 aportou estudos no âmbito da consulta pública no 89/2009, estabelecida pela ANVISA em novembro de 2009, na qual solicitava a apresentação de críticas e sugestões relativas à proposta de Regulamento Técnico, para o ingrediente ativo Metamidofós. $\mathrm{Na}$ oportunidade tentou demonstrar, com argumentos técnicos, que o banimento do produto, na maneira proposta, não era a medida mais adequada. Considerando que aproximadamente $90 \%$ das atividades da empresa giravam em torno do produto atingido pela resolução final, a Fersol manteve seu pedido de acesso aos autos do processo administrativo e aos documentos que embasaram a decisão referida na Resolução da Diretoria Colegiada (RDC ํo. 01/2011) da ANVISA, por isso impetrou recurso ${ }^{6}$ contra esta decisão, para que fosse assegurado o direito de ter conhecimento de todos os atos documentados no processo administrativo, inclusive aqueles que fundamentaram a RDC ํo. 01/2011. Alegou que a ANVISA não deu a ela a possibilidade de intervir ou se defender no processo de reavaliação dos produtos à base de Metamidofós e que o impedimento de fabricação e comercialização se deu com base em estudos antigos, utilizados para reavaliação da substância em 2002.

Em junho de 2011, o Poder Judiciário acatou o recurso da empresa Fersol e suspendeu os efeitos da RDC ㄲo. 01/2011 da ANVISA ${ }^{7}$. Considerou-se o risco de dano irreparável ou de difícil reparação a serem suportados pela empresa a partir da proibição da fabricação de produtos a base do Metamidofós, por responderem por $90 \%$ de sua atividade. Levou-se em conta o fato de que o Metamidofós era ingrediente presente nos produtos de fabricação da Fersol, utilizado no Brasil desde 1993. Ressaltou que no ano

\footnotetext{
6 Seção Judiciária do Distrito Federal - Mandado de Segurança no 3481-05.2011.4.01.3400.

7 Seção Judiciária do Distrito Federal - Processo nํ34141-79.2011.4.01.3400
} 
de 2002 a ANVISA procedeu à reavaliação toxicológica dessa substância e na oportunidade avalizou seu uso, desde que adotadas medidas mitigadoras de riscos.

Entretanto a ANVISA recorreu desta decisão. Em sentença proferida pelo TRF $1^{\text {a }}$ Região, destacou-se:

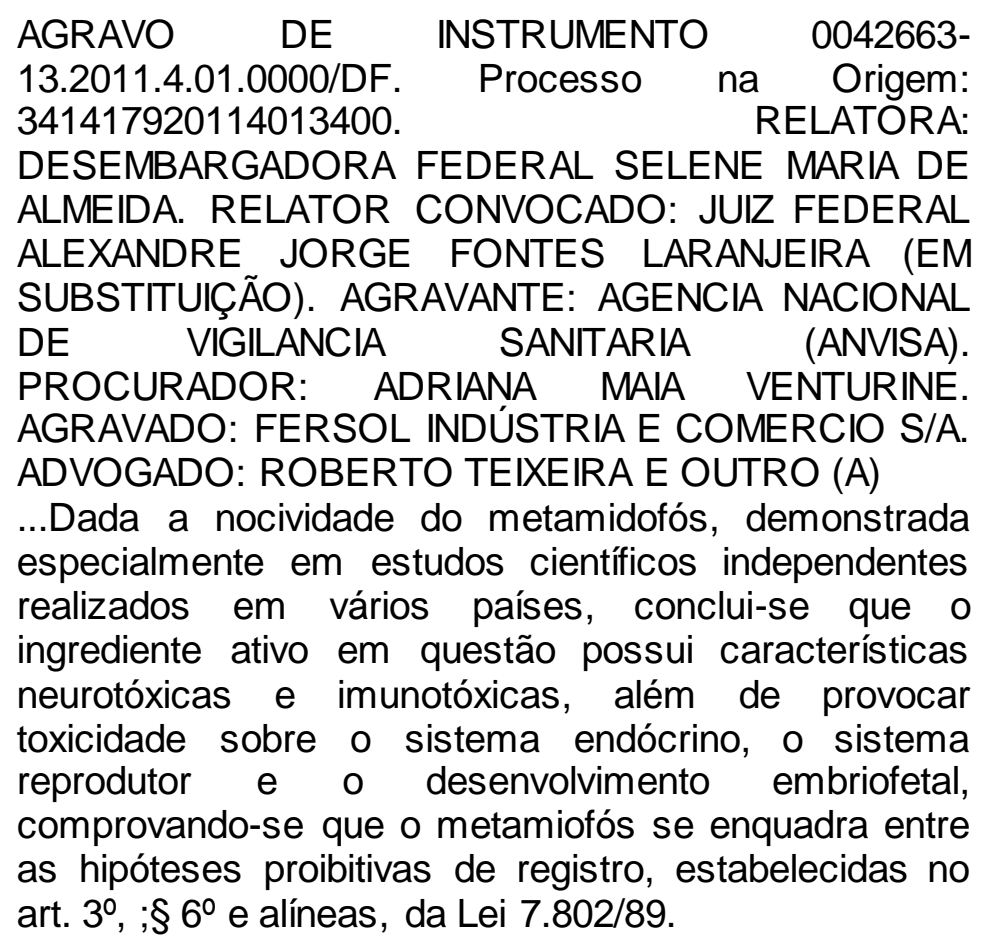

Também apontou que cabe ao Estado impor validamente limitações à livre iniciativa consagrada na Constituição, sobretudo quando se trata de garantir a saúde pública em detrimento dos interesses financeiros de entidades particulares. Neste caso, a livre iniciativa alçada à condição de princípio da ordem econômica, em observância ao artigo 170 da Constituição Federal, não significa a inviabilidade da intervenção do Estado na atividade econômica, na medida em que o artigo 174 da Carta magna é expresso ao afirmar que o Estado exercerá as funções de fiscalização da atividade econômica, dada a sua condição de agente normativo e regulador da ordem econômica.

A sentença ainda ressalta:

A alegação da empresa de que se trata de substância segura, etc., é questão que contraria o entendimento da agência especializada e demanda ampla dilação probatória, não se justificando a pretendida inversão de ordem, com a presunção de que a utilização do produto traga alguma proteção à população, pois tal conduta apenas atende ao interesse econômico da empresa, 
não se justificando obstar a atuação da Agência Sanitária do país no cumprimento de suas atribuições.

Assim, em setembro de 2011, o Poder Judiciário deferiu o pedido de efeito suspensivo requerido para suspender a eficácia da decisão que concedeu antecipação de tutela para autorizar a comercialização do produto a despeito do pronunciamento da ANVISA ${ }^{8}$.

\section{Considerações finais}

Os fatos relacionados à reavaliação e cancelamento do agrotóxico metamidofós mostram a importância da existência do controle sanitário, bem como a necessidade de constantes reavaliações das tecnologias empregadas na produção agrícola brasileira. $\mathrm{O}$ seu efeito acumulativo, prejudicial à saúde humana, nos leva a reflexão sobre o uso intensivo e abusivo de agrotóxicos, bem como o uso não aprovado e em doses não recomendadas desses produtos.

O uso não autorizado do metamidofós, bem como a presença de resíduos acima do limite máximo permitido para as culturas agrícolas, é preocupante. Há a necessidade de se conscientizar os agricultores sobre os riscos que eles assumem ao utilizarem agrotóxicos, sem as devidas precauções que resguardam suas vidas.

O metamidofós faz parte de um conjunto de agrotóxicos que ao longo dos anos contribuiu para o aumento de produtividade da agricultura brasileira. No entanto, trouxe riscos que devem ser avaliados e comparados com os benefícios. A avaliação de risco inicial é limitada, pois o conhecimento mais profundo sobre o risco somente é obtido após o uso constante. Neste sentido, os estudos também devem ser constantes.

O fato é que após vários anos consecutivos de uso consolidou-se uma situação de produção na qual os agricultores se acostumaram ao uso do metamidofós e a sua reavaliação ameaçava interesses econômicos. Mas existe legislação específica sobre o tema, o que dá ao aos poderes públicos competências para realizarem controle sanitário e a reavaliação sistemática do uso de agrotóxicos. Isso ocorre quando há indícios de riscos inerentes ao uso desses produtos ou quando houver alerta de organizações internacionais responsáveis pela saúde, alimentação ou meio ambiente.

\footnotetext{
8 Tribunal Regional Federal da Primeira Região - Agravo de instrumento n. 0042663-13.2011.4.01.0000/DF. Processo Original: 0034141-79.2011.4.01.3400.
} 
O controle sanitário identifica distorções, tais como o uso não racional e não permitido, a falta de consciência do agricultor e a falta de cuidados na aplicação de agrotóxicos. Os conhecimentos trazem informações e evidências sobre os riscos, tanto para a saúde quanto para o ambiente, o que justifica a constante reavaliação. Por isso há leis que preveem novas avaliações de risco sempre que houver necessidade.

Muitas ações judiciais tentam invalidar as reavaliações dos agrotóxicos, principalmente quando estas são contrárias aos interesses das empresas detentoras dos produtos. Assim, são necessários processos bem instrumentados, confiáveis e de qualidade para que o judiciário tome decisões bem fundamentadas. É cada vez mais necessário o diálogo do judiciário com as autoridades sanitárias, pois o conhecimento sobre avaliações de risco não é estanque e deve ser buscado por ser determinante no gerenciamento do risco, cujo propósito principal é proteção da saúde. Assim, pesquisas que avaliem o diálogo do judiciário com autoridades sanitárias são também desejáveis.

\section{Referências}

1 Silva, A B et al. Uso de agrotóxicos no sistema de produção de hortaliças no Município de Camocim de São Félix, Pernambuco. Embrapa Solos, Rio de Janeiro, 1999. 22 p. (Boletim de Pesquisa, n. 6).

2 Sobreira, AEG; Adissi, PJ. Agrotóxicos: falsas premissas e debates. Ciência \& Saúde Coletiva, 8 (4): 985-990, 2003.

3 Vaz, P A B. O direito ambiental e os agrotóxicos: responsabilidade civil, penal e administrativa. Porto Alegre: Livraria do Advogado Editora, 2006. 240 p.

4 OPAS. Organização Pan-Americana da Saúde. Manual de vigilância da saúde de populações expostas a agrotóxicos. Brasilia: OPAS/OMS, 1997.69 p.

5 Júnia, Raquel. Agrotóxicos: um mercado bilionário e cada vez mais concentrado. Escola Politécnica de Saúde Joaquim Venâncio /Fundação Oswaldo Cruz. Disponível em http://www.epsjv.fiocruz.br. [Acesso em 13 set 2012].

6 Anvisa. Agência Nacional de Vigilância Sanitária. Nota técnica reavaliação toxicológica do ingrediente ativo Metamidofós. Gerencia geral de toxicologia. Disponível em http://www.anvisa.gov.br. [Acesso em 24 set 2012].

7 Anvisa. Agência Nacional de Vigilância Sanitária. Agrotóxicos e Toxicologia: Programa de análise de resíduos de agrotóxicos em alimentos: relatório anual. Brasília, 22 de junho de 2010. Disponível em http://www.anvisa.gov.br. [Acesso em 17 out de 2012]. 
8 Brasil. Lei no 7.802, de 11 de julho de 1989. Dispõe sobre a pesquisa, a produção, a embalagem e rotulagem, o transporte, o armazenamento, a comercialização, a propaganda comercial, a utilização, a importação, a exportação, o destino final dos resíduos e embalagens, o registro, a classificação, o controle, a inspeção e a fiscalização de agrotóxicos, seus componentes e afins, e dá outras providências. In: Legislação federal de agrotóxicos e afins. Brasilia: Ministério da Agricultura, Pecuária e Abastecimento, 1998. p. 7-13.

9 Delduque, MC et al. A reavaliação do registro de agrotóxicos e o direito à saúde. Revista de Direito Sanitário, São Paulo, 11 (1):169-175. 2010.

10 Oliveira, SS. O papel da Avaliação de risco no gerenciamento de produtos agrotóxicos: diretrizes para a formulação de políticas públicas. São Paulo, 2005. 236 p. Dissertação (Doutorado em saúde Pública). Universidade de São Paulo.

11 Anvisa. Agência Nacional de Vigilância Sanitária. Reavaliação de agrotóxico: 10 anos de proteção à população. Brasilia, 2 de abril de 2009. Disponível em http://www.anvisa.gov.br. [Acesso em 27 out 2012].

12 Brasil. Decreto oㅜ 4.074, de 4 de janeiro de 2002. Regulamenta a Lei no 7.802, de 11 de julho de 1989, que dispõe sobre a pesquisa, a experimentação, a produção, a embalagem e rotulagem, o transporte, o armazenamento, a comercialização, a propaganda comercial, a utilização, a importação, a exportação, o destino final dos resíduos e embalagens, o registro, a classificação, o controle, a inspeção e a fiscalização de agrotóxicos, seus componentes e afins, e dá outras providências. Diário Oficial da União, Brasilia: 8 de janeiro de 2002.

13 EPSJV. Escola Politécnica de Saúde Joaquim Venâncio. Há muitas evidências de danos dos agrotóxicos à saúde. Fundação Oswaldo Cruz. Disponível em http://www.epsjv.fiocruz.br. Acesso em 24 de setembro de 2012.

13 Edwards, FL.; Tchounwou, PB. Environmental toxicology and health effects associated with methyl parathion exposure - a scientific review. International Journal of Environmental Research and Public Health, 2 (3): 430-441, 2005.

14 Moreira, LF. Diagnóstico dos problemas ecotoxicológicos causados pelo uso de inseticida (metamidofós) na região agrícola de Viçosa - MG. Viçosa, 1995. 95 p. Dissertação (Mestrado em Agroquímica) Universidade Federal de Viçosa.

15 Araújo, S M. Uso de inseticidas nos pólos de produção da ilha de São Luís (MA): condições de trabalho e contaminação de hortaliças. São Luís, 2000. 88 p. Dissertação (Mestrado em Agroecologia). Universidade Estadual do Maranhão

16 Kidd, H; James, DRJ (Eds). The Agrochemicals Handbook. Cambridge: Royal Society of Chemistry Information Services, 1991. $1100 \mathrm{p}$. 
17 Moreira, J C. et al. Avaliação Integrada do impacto do uso de agrotóxicos sobre a saúde humana em uma comunidade agrícola de Nova Friburgo, RJ. Ciência \& Saúde Coletiva, 7 (2): 299-311, 2002.

18 Brasil. Resolução-RDC № 1, de 14 de janeiro de 2011. Regulamento técnico para o ingrediente ativo Metamidofós em decorrência da reavaliação toxicológica. Diário Oficial da União, Brasília: 17 de janeiro de 2011.

19 Rossi, A. Aspectos de aplicabilidade dos instrumentos jurídicos de controle da poluição por agrotóxicos. HOLOS Environment, 1 (2): 173-186, 2001

20 Nodari, RO. Pertinência da Ciência Precaucionária na identificação dos riscos associados aos produtos das novas tecnologias. Disponível em: http://www.ghente.org. [Acesso em 13 de out 2012].

21 AMDA. Associação Mineira de defesa do Ambiente. Utilização de agrotóxicos no Brasil é abusiva. Disponível em http://www.sense8.com.br/clientes/amda. [Acesso em 15 out 2012].

Como citar este artigo:

Oliveira KM. Controle sanitário de agrotóxicos no Brasil: o caso do Metamidofós. Revista Cadernos IberoAmericanos de Direito Sanitário. 2016 abr./jun, 5(2):160-176 